\title{
Comparative Effects of Amlodipine and Candesartan on Blood Pressure and Metabolic Profile in Non-Diabetic Hypertensive Patients
}

\author{
Zeina A Althanoon ${ }^{1, *}$, Imad AJ Thanoon ${ }^{2}$
}

\section{Zeina A Althanoon ${ }^{1, *}$, Imad AJ Thanoon ${ }^{2}$}

'College of Pharmacy, University of Mosul, Mosul, IRAQ.

${ }^{2}$ College of Medicine, University of Mosul, Mosul, IRAQ.

\section{Correspondence}

\section{ZA Althanoon}

College of Pharmacy, University of Mosul, Mosul, IRAQ.

E-mail: Ph.Zeinaalthanoon@yahoo.com History

- Submission Date: 02-11-2021;

- Review completed: 21-12-2021;

- Accepted Date: 17-01-2022.

DOI : 10.5530/pj.2022.14.19

Article Available online

http://www.phcogj.com/v14/i1

\section{Copyright}

(C) 2022 Phcogj.Com. This is an openaccess article distributed under the terms of the Creative Commons Attribution 4.0 International license.

\begin{abstract}
Introduction: The present study aimed to compare the effects of the angiotensin II receptor blocker candesartan and the calcium channel blocker amlodipine on blood pressure and metabolic profile in nondiabetic hypertensive patients. Methods: The study involved non-diabetic patients with mild to moderate hypertension. They were randomly assigned to receive candesartan or amlodipine for 24 weeks, parameters were evaluated at baseline and after 12 weeks and 24 weeks for each patient group. Results: Candesartan and amlodipine both reduced blood pressure and the HOMA-IR index significantly $(P<0.05$, 24 weeks vs. baseline). Candesartan was more effective than amlodipine in lowering blood pressure and HOMA-IR, although the difference was not significant statistically. Conclusion: Both candesartan and amlodipine are extremely effective at reducing blood pressure in moderate hypertension patients. Candesartan cilexetil has a major benefit in terms of tolerability, as it reduces the risk of developing metabolic dysregulation.

Key words: Amlodipine, Candesartan, Hypertension, Insulin resistance.
\end{abstract}

\section{INTRODUCTION}

Because of the associated economic, morbidity and mortality effects on society, hypertension remains a serious public health disorder. It is a significant contributor to cardiovascular, cerebrovascular and renal complications. ${ }^{1,2}$ Various classes of antihypertensive drugs that act via distinct pharmacodynamics mechanisms and are used to treat hypertension are known, and none of them are without adverse metabolic effects. ${ }^{3,4}$ According to available evidence, disorders of carbohydrate and lipid metabolism are more prevalent in hypertensive individuals, asserting that the pathogenic association between diabetes mellitus and hypertension is actually bidirectional. ${ }^{5,6}$ Electrolyte disturbances, dyslipidemia, hyperglycemia or even hypoglycemia, are the adverse reactions that restrict the use of these drugs in hypertensive patients who have comorbid conditions including diabetes mellitus. ${ }^{7,8}$ Medications that function as inhibitors of the angiotensin converting enzyme and antagonists of the angiotensin receptor II provide comparable benefits in terms of cardiovascular mortality and morbidity reduction, they have a distinct adverse effect profile. These drugs, in particular, exhibit a wide range of effects on metabolic parameters such as glucose, insulin, and lipid levels. ${ }^{6,9}$

Hypertensive patients are at risk of developing diabetes mellitus because hypertension impairs glucose tolerance and induces insulin resistance. When diabetes is combined with hypertension, the risk of cardiovascular disease is significantly increased. ${ }^{10}$ As a consequence, it is important that antihypertensive drugs are chosen safely to reduce adverse effects on metabolic parameters, or exacerbate hypertensive patients' already insulin resistant state, but rather prevent hypertensive patients from developing diabetes mellitus. ${ }^{11}$
Dry cough, hyperkalemia, proteinuria, and hypersensitivity reactions being the most common adverse reactions of angiotensin converting enzyme inhibitors although these are the most frequently used drugs for hypertension. There is no evidence that these drugs have a beneficial or detrimental effect on the lipid profile, blood glucose, or insulin levels. ${ }^{12}$ Additionally, the available evidence indicates that angiotensin receptor blockers can improve hyperglycemia and dyslipidemia in patients with diabetes and renal complications, as well as mitigate the adverse effects of hyperglycemia. ${ }^{3}$

Numerous studies have established that angiotensin receptor blockers, particularly candesartan, have a sensitizing effect on the insulin receptor. ${ }^{13}$ Candesartan is a non-tetrozole monocarboxylic acid angiotensin receptor blockers that acts similarly to thiazolidinedione as an agonist at the peroxisome proliferator-activated gamma receptor (PPAR), this illustrates how it has an impact on glucose and insulin metabolism. However, it is unknown whether the entire ARB class shares this beneficial effect on insulin sensitivity. It is believed that CCBs are metabolically inert. The short half-life of nifedipine is associated with decreased insulin sensitivity. Few studies have demonstrated that long-acting calcium channel blockers, such as amlodipine, improve glucose homeostasis and reduce insulin resistance. The aim of study to assess and compare effects of candesartan and amlodipine, two commonly used first-line antihypertensive medications, on glucometabolic parameters and lipid profile in nondiabetic hypertensive patients.

\section{MATERIALS AND METHODS}

The study enrolled fifty non-diabetic patients with mild to moderate hypertension (SBP: 140-159 mmHg 
and/or DBP: 90-99 $\mathrm{mmHg}$ ) aged 18 to 68 years of both sexes, attending the outpatient clinic in IBN-SINA Teaching Hospital. The study was piloted in conformity with the Declaration of Helsinki's principles, and all participants supplied written informed consent before the study's start. Exclusion criteria include patients with diabetes mellitus, a history of hypersensitivity to ARBs/-blockers, renal artery stenosis, acute or chronic renal failure, patients with significant cardiovascular disease, pregnant/lactating women, or women planning to become pregnant. Study approval was made by the Research Ethical Committee at University of Mosul. All biological kits involved in this study were supplied by using BIOLABO kit (France).

\section{Design of the study}

The research design is a prospective, randomized controlled clinical trial. The study's patients were randomly allocated to one of two groups of fifty each to pursue the following treatments orally: Candesartan was orally dosed from 8 to $16 \mathrm{mg}$ daily in Group I; amlodipine was orally dosed from 5 to $10 \mathrm{mg}$ daily in Group II. The patient was started on $8 \mathrm{mg}$ Candesartan or $5 \mathrm{mg}$ amlodipine with daily blood pressure monitoring at four-weekly follow-up visits. For each of these appointments, blood pressure was taken. If the DBP was greater than $90 \mathrm{~mm} \mathrm{Hg}$, the dose was doubled. Patients received the drugs followed up for three months to determine the effects on blood pressure as well as the following biochemical parameters:

Serum glucose level (FSG) and serum insulin level (FPI) were determined using standard techniques on blood samples were collected from subjects following an overnight fast. Insulin concentrations were determined using the enzyme-linked immunosorbent assay (ELISA) technique. The following equation was used to calculate the homeostasis model assessment evaluation for insulin resistance (HOMA-IR) [fasting insulin $(\mu \mathrm{IU} / \mathrm{L}) \mathrm{x}$ fasting glucose $(\mathrm{nmol} / \mathrm{L}) / 22.5$ ]

Standard methods were used to determine lipid profile in serum (HDL-C,TG, Total-C and LDL-C).${ }^{14}$ Friedewald's formula was used to calculate low density LDL-C levels. Blood pressure was measured by using a mercury sphygmomanometer with an appropriately sized cuff that encircled at least $80 \%$ of the arm. Each patient was required to sit for five minutes in a chair while their feet are floor touching and at heart level arms supported in a private, quiet environment with a comfortable room temperature. Blood pressure was measured using the auscultatory process. The average of the two recordings was determined. Body Mass Index was calculated using the Quetelet index formula BMI = Weight in $\mathrm{kg} /\left(\right.$ Height in $\left.\mathrm{m}^{2}\right)$.

Statistical Analysis was performed in which the data is expressed as means \pm SD with a normal distribution and as median (range) for data with a skewed distribution. Inter-group comparisons between candesartan and amlodipine groups were performed using the unpaired Student's t-test for Gaussian data. For intra-group (or between-group) comparisons, analysis of variance (ANOVA) was used to compare different parameters with a normal distribution within the same group at various time points. Tukey Kramer and Dunn's tests were used as posttests with multiple comparisons to determine which group was responsible for the difference between Gaussian and non-Gaussian results.

\section{RESULTS}

One hundred newly diagnosed hypertensive patients were enrolled in the study. The patients were divided into two groups of fifty subjects. One group received candesartan $8-16 \mathrm{mg}$ once daily while the other group receive amlodipine 5-10mg once daily. They were followed up for about three months' duration after receiving treatments.

\section{Effects of candesartan on blood pressure}

The results of the study found that both systolic and diastolic blood pressure were significantly increased $(\mathrm{p}<0.001)$ in hypertensive patients before starting therapy. After therapy with candesartan, a highly significant decrease $(p<0.001)$ in both systolic and diastolic blood pressure after three months of therapy had been obtained (Table 1).

\section{Effects of candesartan on FSG, FSI and HOMA-IR}

FSG, FSI and HOMA-IR were significantly increased $(\mathrm{p}<0.001)$ in patients before starting therapy with candesartan. After therapy with candesartan, a highly significant reduction $(\mathrm{p}<0.001)$ in FSG, FSI and HOMA-IR after three months of therapy had been obtained (Table 2).

\section{Effects of candesartan on lipid profile}

The lipid profile (TC, TG, HDL and LDL cholesterol) was significantly increased $(\mathrm{p}<0.001)$ in hypertensive patients before starting therapy with candesartan. After therapy with candesartan, there were no significant differences in TC, TG and LDL-C after three months of therapy while there was a significant difference $(\mathrm{p}<0.001)$ in HDL-C after three months of therapy with candesartan (Table 3).

\section{Effects of amlodipine on blood pressure}

Both systolic and diastolic blood pressure were significantly increased $(\mathrm{p}<0.001)$ in hypertensive patients before starting therapy with amlodipine. After therapy with amlodipine, a highly significant reduction $(\mathrm{p}<0.001)$ in systolic and diastolic blood pressure after two months of therapy had been obtained (Table 4 ).

Table 1: Effects of candesartan 8mg on blood pressure.

\begin{tabular}{lccc}
\hline \multirow{2}{*}{ Parameter } & \multicolumn{3}{c}{ Mean \pm SD } \\
\cline { 2 - 4 } & Before & After & p-value \\
\hline SBP $(\mathrm{mmHg})$ & $142.50 \pm 6.62$ & $127.60 \pm 6.15$ & $<0.001$ \\
DBP $(\mathrm{mmHg})$ & $94.34 \pm 5.25$ & $83.54 \pm 5.34$ & $<0.001$
\end{tabular}

Using paired t- test $(n=50)$.

Table 2: Effects of candesartan 8mg on FSG, FSI and HOMA-IR level.

\begin{tabular}{lccc}
\hline \multirow{2}{*}{ Parameter } & \multicolumn{3}{c}{ Mean \pm SD } \\
\cline { 2 - 4 } & Before & After & p-value \\
\hline FSG $(\mathrm{mmol} / \mathrm{l})$ & $7.5 \pm 0.4$ & $5.2 \pm 0.6$ & $<0.001$ \\
FSI $(\mu \mathrm{IU} / \mathrm{ml})$ & $11.53 \pm 3.61$ & $9.49 \pm 4.68$ & $<0.001$ \\
HOMA-IR & $2.88 \pm 0.917$ & $1.79 \pm 0.515$ & $<0.001$
\end{tabular}

Using paired t- test $(n=50)$.

Table 3: Effects of candesartan 8mg on lipid profile.

\begin{tabular}{lccc} 
& \multicolumn{3}{c}{ Mean \pm SD } \\
\cline { 2 - 4 } & Before & After & p-value \\
$\mathrm{TC}(\mathrm{mmol} / \mathrm{l})$ & $6.23 \pm 0.70$ & $6.16 \pm 0.71$ & $0.135(\mathrm{NS})$ \\
$\mathrm{TG}(\mathrm{mmol} / \mathrm{l})$ & $1.56 \pm .0 .40$ & $1.47 \pm 0.42$ & $0.240(\mathrm{NS})$ \\
$\mathrm{HDL}(\mathrm{mmol} / \mathrm{l})$ & $1.51 \pm 0.33$ & $2.11 \pm 0.39$ & $<0.001$ \\
$\mathrm{LDL}(\mathrm{mmol} / \mathrm{l})$ & $4.12 \pm 0.65$ & $4.00 \pm 0.70$ & $0.098(\mathrm{NS})$
\end{tabular}

NS= Non-significant.

Table 4: Effects of amlodipine $\mathbf{5 m g}$ on blood pressure.

\begin{tabular}{lccc}
\hline \multirow{2}{*}{ Parameter } & \multicolumn{3}{c}{ Mean \pm SD } \\
\cline { 2 - 4 } & Before & After & p-value \\
\hline $\mathrm{SBP}(\mathrm{mmHg})$ & $147.78 \pm 7.83$ & $135.47 \pm 8.30$ & $<0.001$ \\
$\mathrm{DBP}(\mathrm{mmHg})$ & $90.56 \pm 6.15$ & $82.08 \pm 5.23$ & $<0.001$
\end{tabular}

Using paired t- test $(n=50)$. 


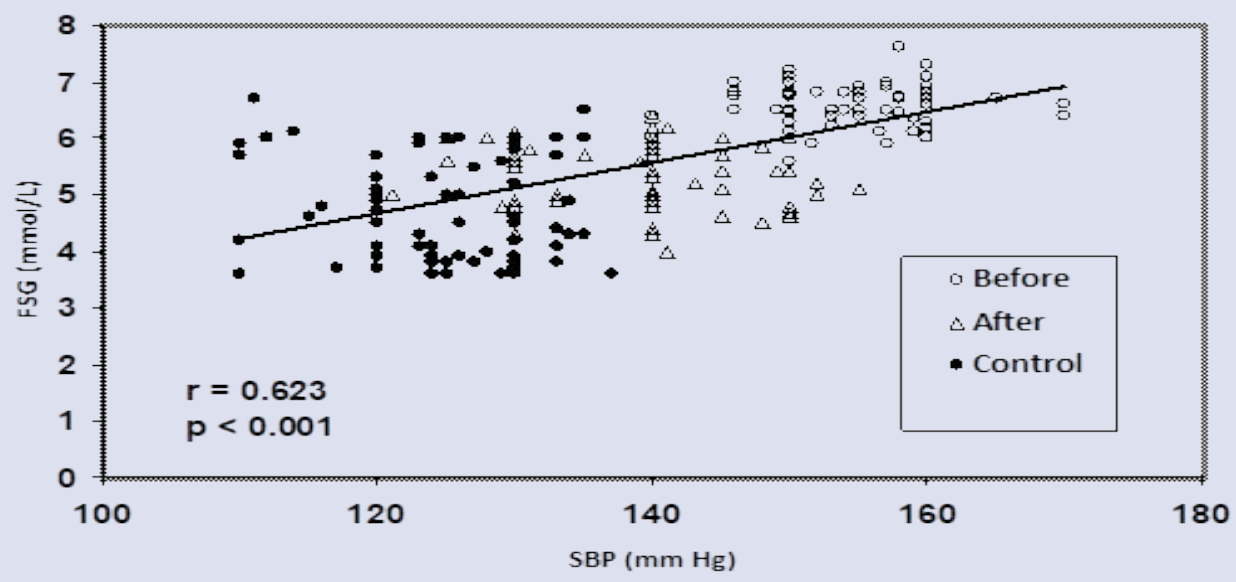

Figure 1: Relationship between systolic blood pressure and FSG levels in the candesartan and control groups.

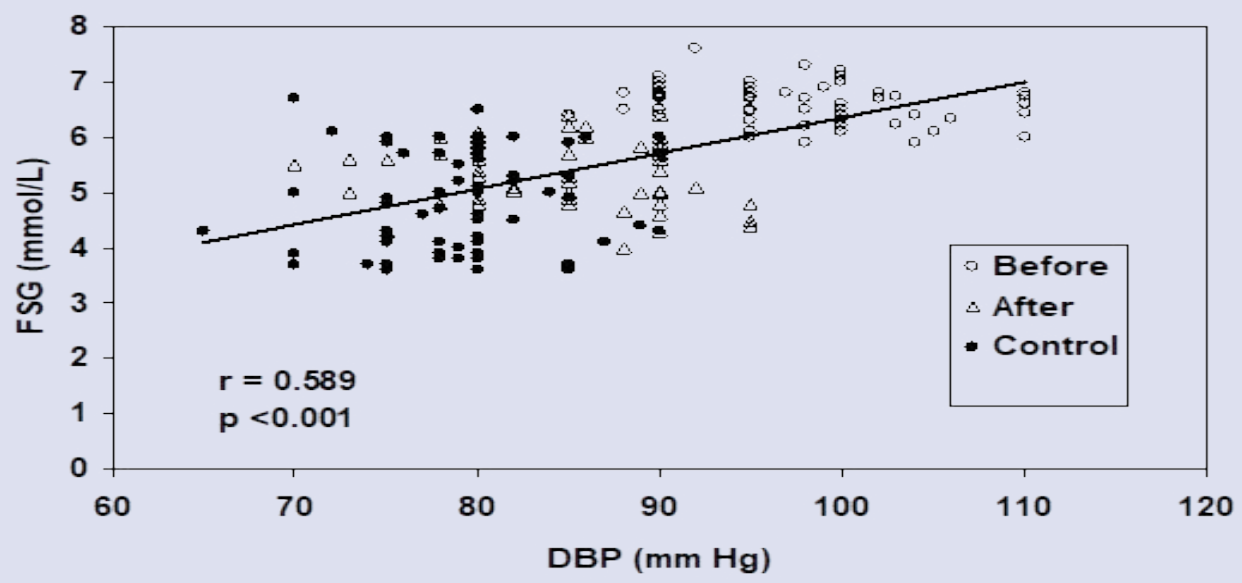

Figure 2: Relationship between diastolic blood pressure and FSG levels in the candesartan and control groups.

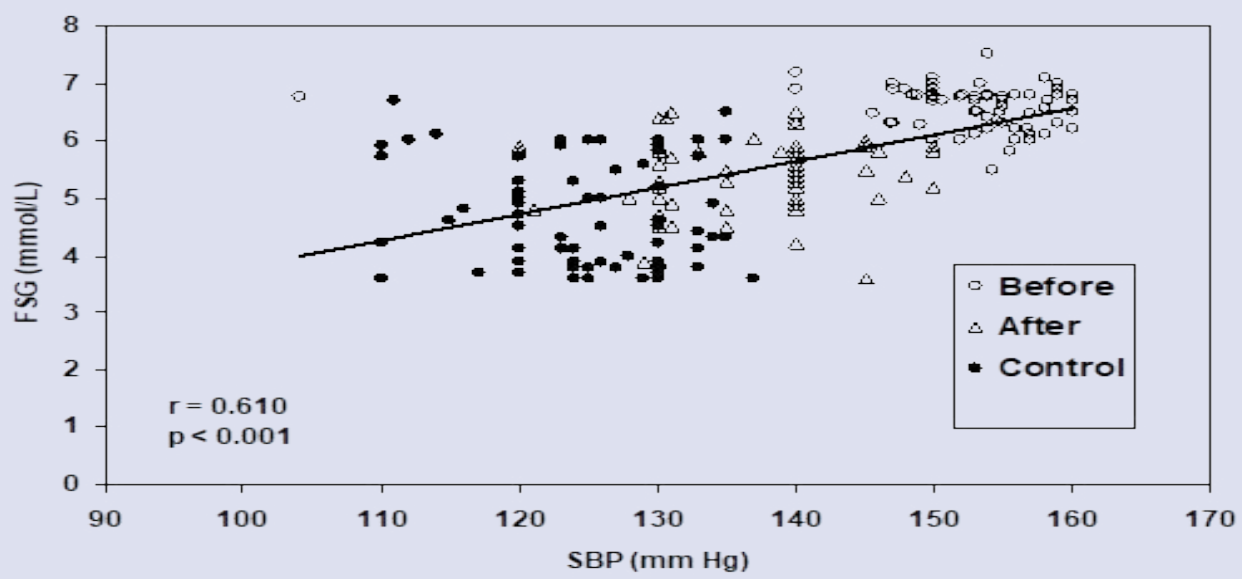

Figure 3: Relationship between systolic blood pressure and FSG levels in the amlodipine and control groups. 


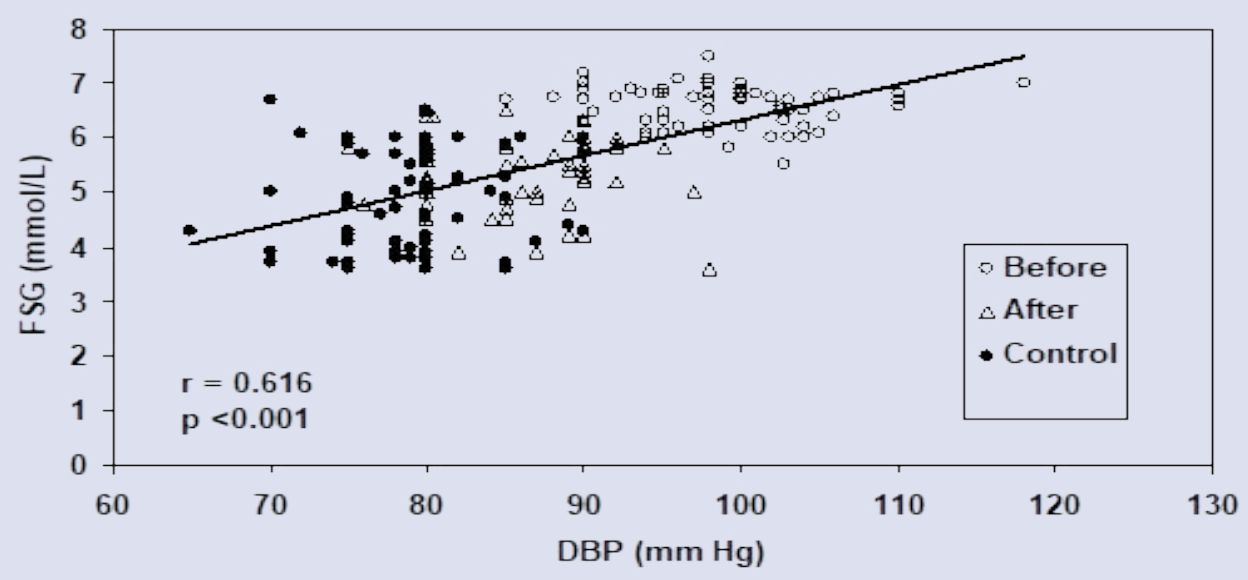

Figure 4: Relationship between diastolic blood pressure and FSG levels in the amlodipine and control groups.

Table 5: Effects of amlodipine $5 \mathrm{mg}$ on fasting serum glucose.

\begin{tabular}{lccc}
\hline \multirow{2}{*}{ Parameter } & \multicolumn{3}{c}{ Mean \pm SD } \\
\cline { 2 - 4 } & Before & After & p-value \\
\hline FSG $(\mathrm{mmol} / \mathrm{l})$ & $6.55 \pm 0.38$ & $5.35 \pm 0.66$ & $<0.001$ \\
FSI $(\mu \mathrm{IU} / \mathrm{ml})$ & $10.26 \pm 3.30$ & $8.42 \pm 2.56$ & $<0.001$ \\
HOMA-IR & $2.72 \pm 0.93$ & $2.01 \pm 0.634$ & $<0.001$
\end{tabular}

Using paired $t$ - test $(n=50)$.

Table 6: Effects of amlodipine $5 \mathrm{mg}$ on lipid profile.

\begin{tabular}{|c|c|c|c|}
\hline \multirow{2}{*}{ Parameter } & \multicolumn{3}{|c|}{ Mean \pm SD } \\
\hline & Before & After & p-value \\
\hline Total(mmol/l) & $7.33 \pm 0.80$ & $6.63 \pm 1.00$ & $0.234(\mathrm{NS})$ \\
\hline $\mathrm{TG}(\mathrm{mmol} / \mathrm{l})$ & $1.36 \pm 0.50$ & $1.27 \pm 0.50$ & $0.371(\mathrm{NS})$ \\
\hline $\mathrm{HDL}(\mathrm{mmol} / \mathrm{l})$ & $1.56 \pm 0.40$ & $1.70 \pm 0.37$ & 0.136 (NS) \\
\hline $\mathrm{LDL}(\mathrm{mmol} / \mathrm{l})$ & $4.32 \pm 0.81$ & $4.38 \pm 0.80$ & 0.618 (NS) \\
\hline
\end{tabular}

Using paired t- test $(\mathrm{n}=50)$.

NS= Not significant

Table 7: Comparison of percent variation of the studied parameters after therapy with candesartan or amlodipine.

\begin{tabular}{lccc}
\hline & \multicolumn{2}{c}{ Mean \pm SD $(\%)$} & \\
\cline { 2 - 3 } Parameter & $\begin{array}{c}\text { Candesartan } \\
(\mathrm{n}=50)\end{array}$ & $\begin{array}{c}\text { Amlodipine } \\
(\mathrm{n}=50)\end{array}$ & p-value \\
SBP $(\mathrm{mmHg})$ & $-11.23 \pm 6.29$ & $-10.55 \pm 5.43$ & $0.194(\mathrm{NS})$ \\
DBP $(\mathrm{mmHg})$ & $-10.70 \pm 7.1$ & $-9.60 \pm 7.18$ & $0.157(\mathrm{NS})$ \\
FSG $(\mathrm{mmol} / \mathrm{l})$ & $-19.4 \pm 10.34$ & $-17.85 \pm 11.34$ & $0.067(\mathrm{NS})$ \\
FSI $((\mu \mathrm{IU} / \mathrm{ml})$ & $-2.5 \pm 17.46$ & $-2.18 \pm 15.22$ & $0.374(\mathrm{NS})$ \\
HOMA-IR & $-3.5 \pm 25.13$ & $-4.27 \pm 14.36$ & $0.196(\mathrm{NS})$ \\
Total-C $(\mathrm{mmol} / \mathrm{l})$ & $-2.8 \pm 16.23$ & $-0.87 \pm 14.99$ & $0.543(\mathrm{NS})$ \\
TG $(\mathrm{mmol} / \mathrm{l})$ & $-5.8 \pm 11.05$ & $-6.62 \pm 13.15$ & $0.325(\mathrm{NS})$ \\
HDL-C $(\mathrm{mmol} / \mathrm{l})$ & $12.40 \pm 20.17$ & $3.46 \pm 19.8$ & $<0.001$ \\
LDL-C $(\mathrm{mmol} / \mathrm{l})$ & $-7.85 \pm 29.12$ & $-5.9 \pm 33.61$ & $0.075(\mathrm{NS})$
\end{tabular}

NS=Not significant using unpaired t-test.

Negative sign means decrease.

Table 8: Correlation between blood pressure and FSG level in patients groups.

\begin{tabular}{lcccc}
\hline \multirow{2}{*}{ Parameter } & \multicolumn{2}{c}{ Systolic Blood Pressure } & \multicolumn{2}{c}{ Diastolic Blood Pressure } \\
\cline { 2 - 5 } & $\mathbf{R}$ & $\mathrm{p}$-value & $\mathrm{R}$ & $\mathrm{p}$-value \\
\hline FSG $(\mathrm{mmol} / \mathrm{l})$ & 0.623 & 0.01 & 0.60 & 0.01
\end{tabular}

\section{Effects of amlodipine on FSG, FSI and HOMA-IR level}

The serum glucose, serum insulin and Insulin resistance levels were significantly increased $(\mathrm{p}<0.001)$ in hypertensive patients before starting therapy. After therapy with amlodipine, a highly significant reduction in these parameters after two months of therapy had been obtained (Table 5).

\section{Effects of amlodipine on lipid profile}

The lipid profile (TC, TG, HDL and LDL cholesterol) was significantly increased $(p<0.001)$ in hypertensive patients before starting therapy with amlodipine. After therapy with amlodipine, a non-significant statistical difference in TC, TG, HDL and LDL cholesterol after two months of therapy had been obtained (Table 6).

Comparision between the statistical percent of variations for the parameters after therapy with candesartan or amlodipine

Table 7 shows a comparison between the percent variations of the parameters after therapy with candesartan or amlodipine. A nonsignificant difference has been obtained with all studied parameters except for the HDL-C level. A significant elevation of HDL-C was obtained with candesartan as compared with amlodipine $(\mathrm{p}<0.001)$.

In all studied groups, a significant positive correlation between systolic blood pressure and fasting serum glucose level (FSG) was observed. Additionally, a significant positive association existed between diastolic blood pressure and FSG concentration in all studied groups ( $\mathrm{r}$ $=0.623, \mathrm{p}=0.01$ ) and a significant negative correlation between diastolic blood pressure and FSG level in all studied groups. $r=0.60$ $(\mathrm{p}=0.01)$ (Table 8).

\section{DISCUSSION}

Current hypertension guidelines recommend four categories of antihypertensive medications, including rennin angiotensin inhibitors, beta adrenergic blockers, calcium channel blockers, and diuretics, to help prevent potential cardiovascular events. Antihypertensive medication selection can be influenced by the patient's ethnic origin, age, or preferred indications. ${ }^{15}$

Although both angiotensin receptor blockers (ARBs) and calcium channel blockers (CCBs) are appropriate for initiating antihypertensive therapy, trials comparing the effectiveness and protection of ARBs 
and CCBs are minimal, and there is no proven study comparing their clinical results over long periods of time in a real world situation..$^{16,17}$

The renin angiotensin aldosterone system (RAAS) is essential to promoting insulin resistance. Angiotensin II-induced vasoconstriction impairs tissue blood flow, further impairing glucose utilization. ${ }^{18}$ Angiotensin II inhibits phosphatidylinositol (PI) 3-kinase activation by phosphorylating insulin receptor substrates (IRS)-1 through Janus kinase 2 (JAK2) enzyme linked to the AT1 receptor. This impairs insulin signaling and results in the development of insulin resistance. ${ }^{19}$

Additionally, angiotensin II is associated with an increase in oxidative stress, which further impairs insulin sensitivity. RAAS plays a major role in rising skeletal muscle TNF- levels, which impairs glucose transporter (GLUT) translocation and thus glucose utilization. Angiotensin II promotes adipose tissue hypertrophy and preadipocyte differentiation, respectively, through its AT1 and AT2 receptors. Insulin resistance is promoted by cytokines released from this hypertrophied adipose tissue. ${ }^{20}$ Thus, angiotensin receptor blockers (ARBs) exert their beneficial effects on glucose homeostasis through a variety of mechanisms involving angiotensin-II inhibition.

Our results are in contrast previous research indicating that angiotensin receptor blocker does not increase insulin sensitivity. A study compared the effect of telmisartan $(80 \mathrm{mg} /$ day $)$ versus losartan $(50 \mathrm{mg} /$ day $)$ on insulin resistance in hypertensive patients with metabolic syndrome using the HOMA-IR. The mean HOMA-IR levels in the losartan group at baseline and at the end of the analysis were 1.80.6 and 1.80.6, respectively $(\mathrm{P}>0.05) .^{21}$

Yavuz et al., (2003) investigated the effects of enalapril 5-40 mg versus losartan 50-100 mg daily on insulin resistance and endothelial function over a six-month period. At six months, the losartan group did not exhibit a substantial decrease in HOMA-IR levels $(2.3+0.6$ to $1.5+0.7$, $\mathrm{P}>0.05) .{ }^{22}$ Huang et al. (2011) examined the effects of telmisartan and losartan, both of which were administered for 16 weeks, on body fat distribution and insulin sensitivity in obese Chinese hypertensive patients. The losartan group did not exhibit a significant improvement in HOMA-IR levels. ${ }^{23}$

Perl et al., (2010) investigated the antihypertensive and metabolic effects of telmisartan and losartan in hypertensive patients with reduced glucose tolerance after 12 weeks of treatment. Insulin resistance was assessed using the HOMA-IR method. Insulin sensitivity was not improved by losartan (baseline: 3.04 \pm 0.60 , after losartan treatment: $3.38 \pm 0.84, \mathrm{P}>0.05) .{ }^{24}$ Moan et al. investigated the effects of losartan $50-100 \mathrm{mg}$ daily on the glucose and insulin metabolism in patients with moderate hypertension for four weeks. ${ }^{2}$ The euglycemic glucose clamp technique was used to determine insulin sensitivity. Losartan has no detectable effect on insulin sensitivity. Also, Siegel et al., demonstrated that losartan improved insulin sensitivity in patients with severe hypertension. ${ }^{25}$

The difference between these studies and ours about candesartan's impact on insulin resistance may be explained by dosage variations, duration of losartan therapy, severity of hypertension, presence of non-diabetic patients, or other unknown variables. ${ }^{4}$ Numerous studies confirm our findings regarding amlodipine's impact on glucometabolic parameters. According to Ersoy et al., amlodipine administered at doses of 5-10 mg daily for 12 weeks to type 2 diabetic hypertensive patients decreased HOMA-IR from 5.591 .0 to $3.610 .5(\mathrm{P}<0.05) .{ }^{8}$

In general, CCBs are believed to have a favorable effect on insulin sensitivity. Similar finding was reported by Al-Thanoon et al. ${ }^{6}$ However, they can perform a function other than being metabolically neutral. ${ }^{15}$ CCBs may help to reduce insulin resistance by acting as a vasodilator, particularly in insulin-sensitive tissues, while having a negligible effect on sympathetic nervous system activity. ${ }^{26} \mathrm{CCBs}$ can aid in the signal transduction of glucose transporters and protect glycogen synthase enzyme from calcium inhibition. The improvement in insulin sensitivity caused by CCBs could be related to their antioxidant properties. ${ }^{26}$

Insulin resistance in obese patients is associated with increased intracellular calcium levels. Thus, calcium channel blockers with a long half-life can improve insulin sensitivity by limiting intracellular calcium. ${ }^{27}$ Additional calcium channel blockers, such as nicardipine, amlodipine and manidipine have been shown in laboratory and clinical trials to reduce TNF-a levels. TNF-a is a pro-inflammatory cytokine developed by adipose tissue and has been linked to the development of obesity-related insulin resistance. ${ }^{15}$

One significant drawback of this study is that the mechanisms by which candesartan and amlodipine improve insulin resistance were not established. Given that approximately $50 \%$ of hypertensive patients are insulin resistant, our research makes a significant contribution. Our research is one of the few to examine the effect of antihypertensive drugs on insulin sensitivity and metabolic profiles in hypertensive patients prior to the onset of diabetes.

\section{CONCLUSION}

Resistance in patients with mild to moderate hypertension, as shown in our study. Additionally, this study emphasizes the serious importance of identifying an antihypertensive medication that does not increase the likelihood of developing diabetes mellitus in hypertensive patients.

\section{ACKNOWLEDGEMENT}

We thank the regional research ethics committees at the University of Mosul, College of Pharmacy and Health Administration Research Technical Support for their Ethics approval of the study. We are grateful to all of the medical staff of out-patient clinic in IBN-SINA Teaching Hospital in Mosul city for their support in carrying out the requirement of the research study.

\section{FUNDING}

Self-funded.

\section{ADHERENCE TO ETHICAL STANDARDS}

The study was approved by an ethical committee in the university of Mosul.

\section{CONFLICTS OF INTEREST}

The authors declare that there is no conflicts of interest.

\section{REFERENCES}

1. Merkhan M, Mohammad J, Fathi Z, Younis Z, Mahmood S, Mohammed M. Silent hyperlipidaemia modulated vascular endothelial markers. Pharmacia. 2021;68:479.

2. Turner ST, Boerwinkle E. Genetics of blood pressure, hypertensive complications, and antihypertensive drug responses. Pharmacogenomics. 2003;4(1):53-65.

3. Almukhtar HM, Faisal IM, Merkhan MM. Acute effect of atorvastatin in comparison with rosuvastatin on glucose homeostasis in hypercholesteremic patients. Pharmacology. 2021;25.

4. PatAmerican Diabetes Association. Standards of medical care in diabetes-2017 abridged for primary care providers. Clinical diabetes: a publication of the American Diabetes Association. 2017;35(1):5.

5. Yeswanthi S, Jayakumari S. A Prospective Study on Combinational Drug Efficacy in Hypertensive Patients. Research Journal of Pharmacy and Technology. 2018;11(2):509-12.

6. Zivkovic AM, German JB, Sanyal AJ. Comparative review of diets for the metabolic syndrome: implications for nonalcoholic fatty liver disease. The American journal of clinical nutrition. 2007;86(2): 285-300. 
7. Faisal IM, Merkhan MM, Almukhtar HM. Effect of chronic Allopurinol therapy on Thyroid function in patients with urate stones. Journal of Advanced Pharmacy Education and Research. 2020;10(4):5.

8. Ramasubramaniyan P, Palanichamy S, Deepu VM, Rajesh M. Formulation and evaluation of amlodipine besylate floating tablets. Res J Phar BiolChem Sci. 2013;4(4):15-33.

9. Almukhtar HM, Faisal IM, Merkhan MM. Effects of statins on platelet count in hyperlipidemic patients. International Journal of Pharmaceutical Research. 2020;12(2).

10. Merkhan MM, Abdullah $\mathrm{KS}$. The role of vitamin $\mathrm{C}$ and $\mathrm{E}$ in improving hearing loss in patients with type 2 diabetes. Annals of the College of Medicine, Mosul. 2020;41(2):184-9.

11. Merkhan MM. The effects of glibenclamide on thyroid function tests in type 2 diabetic patients. Iraqi Journal of Pharmacy. 2013;13(2):55-61.

12. Sidorenkov G, Navis G. Safety of ACE inhibitor therapies in patients with chronic kidney disease. Expert opinion on drug safety. 2014;13(10):1383-1395

13. Kurtz TW, Klein U. Next generation multifunctional angiotensin receptor blockers. Hypertension Research. 2009;32(10):826-34.

14. Sugiura T, Dohi Y, Yamashita S, Yamamoto K, Wakamatsu Y, Tanaka S, et al. Impact of lipid profile and high blood pressure on endothelial damage. Journal of Clinical Lipidology. 2011;5(6):460-6.

15. Blackburn DF, Wilson TW. Antihypertensive medications and blood sugar: theories and implications. Canadian Journal of Cardiology. 2006;22(3):229-33

16. Chobanian AV, Bakris GL, Black HR, Cushman WC, Green LA, Izzo Jr JL, et al. Seventh report of the joint national committee on prevention, detection, evaluation, and treatment of high blood pressure. hypertension. 2003;42(6):1206-52.

17. Taylor EN, Hu FB, Curhan GC. Antihypertensive medications and the risk of incident type 2 diabetes. Diabetes Care. 2006;29(5):1065-70.

18. Messerli FH, Grossman E. Diabetes, hypertension, and cardiovascular disease: An update. Hypertension. 2001;38(3):10651070.
19. Fukao K, Shimada K, Hiki M, Kiyanagi T, Hirose K, Kume A, et al. Effects of calcium channel blockers on glucose tolerance, inflammatory state, and circulating progenitor cells in non-diabetic patients with essential hypertension: a comparative study between Azelnidipine and amlodipine on glucose tolerance and endothelia function-a crossover trial (AGENT). Cardiovascular Diabetology. $2011 ; 10(1): 1-7$

20. Kurtz TW, Pravenec M. Antidiabetic mechanisms of angiotensinconverting enzyme inhibitors and angiotensin II receptor antagonists: beyond the renin-angiotensin system. Journal of hypertension. 2004;22(12):2253-61.

21. Ichikawa Y. Comparative effects of telmisartan and valsartan on insulin resistance in hypertensive patients with metabolic syndrome. Internal Medicine. 2007;46(17):1331-6.

22. Yavuz D, Koç M, Toprak A, Akpınar I, Velioğlu A, Deyneli O, et al. Effects of ACE inhibition and AT1-receptor antagonism on endothelial function and insulin sensitivity in essential hypertensive patients. Journal of the Renin-Angiotensin-Aldosterone System. 2003;4(3):197-203.

23. Huang GZ, Tang $Y H$, Wang BY, Zhang B, Hu TJ, Zhang $L$, et al Effects of telmisartan on insulin resistance and visceral fat distribution in Chinese hypertensive patients with obesity. Saudi Med J. 2011;32(10):1017-21.

24. Perl S, Schmölzer I, Sourij $H$, Pressl $H$, Eder $M$, Zweiker $R$, et al. Telmisartan improves vascular function independently of metabolic and antihypertensive effects in hypertensive subjects with impaired glucose tolerance. International journal of cardiology. 2010;139(3):289-96

25. Siegel D, Swislocki AL. Effects of antihypertensives on glucose metabolism. Metabolic Syndrome and Related Disorders. 2007;5(3):211-9.

26. Aksnes TA, Seljeflot I, Torjesen PA, Höieggen A, Moan A, Kjeldsen SE. Improved insulin sensitivity by the angiotensin II-receptor blocker losartan is not explained by adipokines, inflammatory markers, or whole blood viscosity. Metabolism. 2007:56(11):1470-7.

27. Moan A, Hoieggen A, Seljeflot I, Risanger T, Arnesen $H$, Kjeldsen $\mathrm{SE}$. The effect of angiotensin II receptor antagonism with losartan on glucose metabolism and insulin sensitivity. J Hypertens. 1996;14(9):1093-7.

\section{GRAPHICAL ABSTRACT}

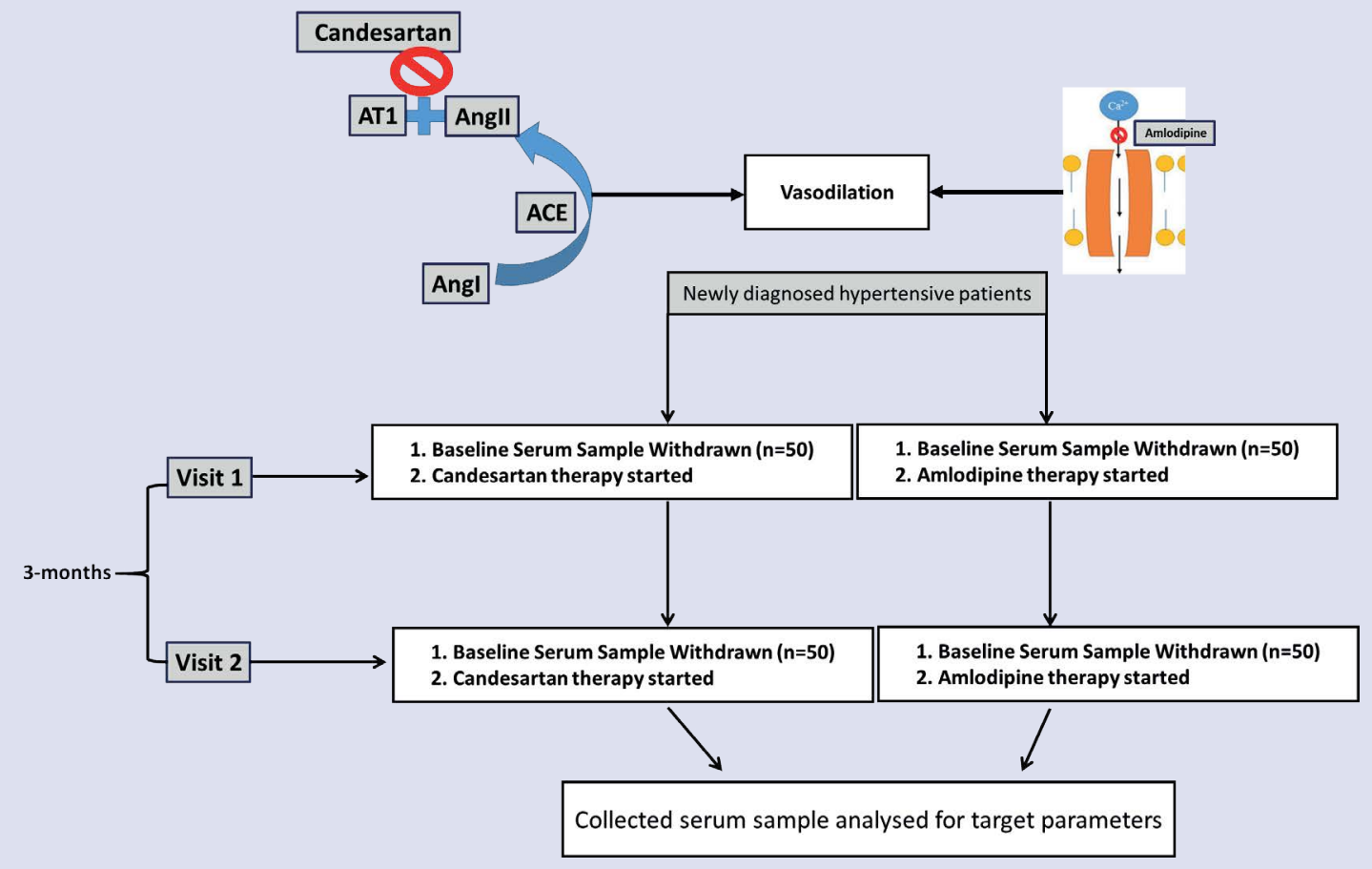




\section{ABOUT AUTHORS}

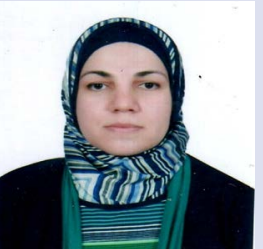

Zeina A Althanoon

Zeina is the Dean of the College of Pharmacy since 2019-present. She is an Assistant Professor of pharmacology at the department of pharmacology and Toxicology, College of Pharmacy at the University of Mosul, Mosul, Iraq.. She has been graduated from college of Pharmacy, University of Mosul and She did her Master and PhD degree in Clinical Pharmacology in College of Medicine at the University of Mosul.

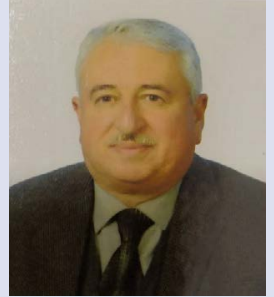

\section{Imad AJ Thanoon}

Imad is currently a Professor of pharmacology at the department of pharmacology, College of Medicine at the University of Mosul, Mosul, Iraq. He is the Head of the department of Pharmacology in the College of Medicine since 2020-present. He has been graduated from college of Medicine, University of Mosul and He did his Master and PhD degree in Clinical Pharmacology in College of Medicine at the University of Mosul.

Cite this article: Althanoon ZA, Thanoon IAJ. Comparative Effects of Amlodipine and Candesartan on Blood Pressure and Metabolic Profile in Non-Diabetic Hypertensive Patients. Pharmacogn J. 2022;14(1): 141-147. 